\title{
Catadores de Material Reciclável e Identidade Social: Uma Visão a Partir da Pertença Grupal
}

\author{
Tereza Glaucia Rocha Matos, Luciana Maria Maia \& Regina Heloisa Maciel \\ Universidade de Fortaleza, Fortaleza, Brasil
}

\begin{abstract}
RESUMO
Este trabalho objetivou analisar a identidade social de catadores de material reciclável, ligada às posições que ocupam na sociedade, decorrentes de suas pertenças sociais. Realizaram-se grupos focais com catadores de depósitos e de associações. Os discursos mostram que os catadores reconhecem os estigmas atribuídos à sua atividade e que permanecem nela por falta de outras oportunidades de trabalho. Nos catadores associados destaca-se uma visão mais crítica acerca do papel que desempenham na sociedade, pois sua participação nessa organização torna possível a mudança da realidade social e de como são percebidos. Conclui-se que os catadores não conseguem vislumbrar uma identidade social própria, escolhida, mas sim uma identidade cuja construção decorre da consciência de integrarem uma categoria de trabalhadores.
\end{abstract}

Palavras-chave: catadores; identidade social; associação de trabalhadores.

\section{ABSTRACT \\ Recycable Materials Collectors and Social Identify From the Point of View of Group Membership}

This work analyzes the recyclable material collectors' social identity, linked to the position they occupy in society as a consequence of their social membership. Focus groups took place with collectors from associations and deposits. Their discourse shows recognition of the stigmas attached to their activity and also that they persist as collectors for lack of other employment opportunities. Associated collectors have a more critical view about their role in society: being an associated collector makes it possible to change their social reality and also the way they are perceived by others. We conclude that collectors cannot envision a chosen, particular social identity, but an identity built from the awareness of belonging to a professional category.

Keywords: collectors; social identity; workers association.

A catação de materiais recicláveis representa, para muitos trabalhadores, a única forma de garantir a sobrevivência e a possibilidade de inclusão num mercado de trabalho excludente (Medeiros \& Macedo, 2006). O segmento populacional, geralmente proveniente das classes menos favorecidas dos centros urbanos, que se dedica a essa atividade, é conhecido como catadores ou coletores de lixo. Embora algumas vezes esses dois termos sejam tomados como sinônimos é possível fazer a distinção entre eles. A Classificação Brasileira de Ocupações (CBO) (Ministério do Trabalho e Emprego, 2010) diferencia as ocupações de catador e coletor, sobretudo, em virtude do tipo de vín- culo que assumem esses trabalhadores. Os catadores se organizam de forma autônoma, em cooperativas ou associações, e vendem o material coletado a empresas e/ou a atravessadores. Segundo Sousa e Mendes (2006), os ligados a uma cooperativa ou associação se organizam sob uma lógica associativista e, geralmente, experimentam uma maior variedade de funções, que incluem puxar ou conduzir carrinhos, catar, separar, pesar, enfardar e vender o material. Os coletores, por outro lado, são funcionários de empresas públicas ou privadas responsáveis pela limpeza da cidade e, nesse sentido, são assalariados e gozam de benefícios legais. Esses profissionais atuam na coleta de resíduos domi- 
ciliares e resíduos sólidos dos serviços de saúde e na limpeza e conservação de áreas públicas, que também inclui a coleta dos resíduos encontrados. Esse material é acondicionado e encaminhado para aterros sanitários.

Neste trabalho, considerando a distinção apresentada, o termo catador de material reciclável é utilizado para designar o indivíduo que, com fins profissionais, mas sem registro trabalhista, individualmente ou em grupo, de forma manual e espontânea, cata, separa e vende materiais que podem ser reaproveitados. Esses materiais incluem papel, papelão e vidro, materiais ferrosos e não ferrosos disponíveis em locais públicos ou privados, lixões ou aterros sanitários. Nessa atividade podem fazer uso de carrinhos, carroças ou sacos como instrumentos de trabalho (Ministério do Trabalho e Emprego, 2010).

Popularmente, os resíduos sólidos têm recebido a denominação de lixo. Segundo Juncá (2004), enquadra-se nesse termo tudo aquilo que é produzido pela sociedade e que por ela é negado e ignorado, devendo por isso ser descartado de forma a manter uma distância segura. Dados de uma pesquisa desenvolvida pela Associação Brasileira de Empresas de Limpeza Pública e Resíduos Especiais (ABRELPE) indicam que em 2009 foram produzidos no Brasil, aproximadamente, 57 milhões de toneladas de resíduos sólidos urbanos, o que representa 359,4 quilogramas por habitante. Considerando dados do Nordeste, a produção de resíduos sólidos em 2009 foi de aproximadamente 47.665 toneladas por dia, o que significa 1,255 quilogramas por habitante. Destaca-se que do total de resíduos produzidos no Brasil, em 2009, cerca de sete milhões de toneladas não foram coletadas. Quando se analisa esse resultado por região, constata-se que no Nordeste somente $22 \%$ dos resíduos produzidos foram coletados. Em relação ao destino final dos resíduos coletados, os dados indicam que, em 2009, 57\% dos resíduos foram encaminhados para aterros sanitários, enquanto que $43 \%$ (cerca de 22 milhões de toneladas) foram deixados em lixões ou em aterros controlados (ABRELPE, 2009). Medeiros e Macedo (2007) afirmam que esse material jogado fora significa a efetiva possibilidade de existência de milhares de pessoas.

A atividade de catador existe de modo informal no Brasil desde o início do século XX, inicialmente na figura do velho garrafeiro, mas rapidamente modificada e ampliada, resultado do acelerado processo de industrialização (Juncá, 2001). A partir da década de 1980, grupos de catadores começaram a se organizar, criando cooperativas e associações, e a lutar pelo reconhecimento dessa atividade como profissão. Nos anos de 1990, apoiados por organizações não governamentais, esses trabalhadores realizaram os primeiros encontros para debater, entre outras questões, o reconhecimento da profissão de catador. O desenrolar desse processo favoreceu a realização, em 2001, do $1^{\circ}$ Congresso Nacional de Catadores de Materiais Recicláveis e a $1^{a}$ Marcha da População de Rua. A culminância desses acontecimentos possibilitou a criação do Movimento Nacional de Catadores (Medeiros \& Macedo, 2006). As ações mencionadas e a organização desse movimento trouxeram resultados políticos significativos para esse segmento de trabalhadores, dentre os quais a incorporação da atividade de catador de material reciclável na CBO. Além disso, o Governo Federal criou o comitê de inclusão social de catadores de lixo, responsável pela implantação de projetos que garantam condições dignas de vida e trabalho à população catadora de lixo, bem como pelo apoio à gestão e ao encaminhamento adequado de resíduos sólidos nos municípios brasileiros (Medeiros \& Macedo, 2006).

Em 2010 foi decretada e sancionada a Lei n. 12.305, que instituiu a Política Nacional de Resíduos Sólidos (Lei n. 12.305, de 02 de agosto de 2010), estabelecendo princípios, objetivos, instrumentos e diretrizes relativas à gestão integrada, ao gerenciamento de resíduos sólidos, às responsabilidades dos geradores e do poder público, bem como aos instrumentos econômicos aplicáveis. Destaca-se nessa política o conceito de responsabilidade compartilhada sobre o destino de resíduos - cada integrante da cadeia produtiva passa a ser responsável, juntamente com os gestores e agentes de limpeza urbana, pelo ciclo de vida completo dos produtos. Aqui vale ressaltar que a política estabelece como fundamental a coleta seletiva: a separação prévia dos resíduos sólidos de acordo com sua constituição ou composição por parte de seus geradores. De modo a viabilizar a coleta seletiva, a política incentiva a organização de catadores de materiais recicláveis por meio da criação e do apoio a cooperativas e outras formas de associação, favorecendo a geração de emprego e renda e, consequentemente, contribuindo para a inclusão social e a emancipação econômica desses trabalhadores (Lei n. 12.305, de 02 de agosto de 2010).

Constata-se um relativo avanço na organização dos catadores e da sociedade em relação ao gerenciamento dos resíduos sólidos nas últimas décadas. Esses acontecimentos têm contribuído, ainda que de forma discreta, para mudar a condição desses trabalhadores e amenizar os impactos sociais decorrentes da produção de resíduos sólidos. Os dados da ABRELPE (2009) 
sugerem um baixo índice de reciclagem de resíduos sólidos. Sobre esse aspecto, pesquisa desenvolvida pelo Instituto de Pesquisa Econômica Aplicada (IPEA) (2010) indica que seguramente a reciclagem traria significativos benefícios econômicos, ambientais e sociais para o País. No que se refere aos catadores enquanto categoria de trabalhadores, os avanços se evidenciam na forma como alguns grupos têm se organizado, seja em associações ou cooperativas, buscando uma participação mais ativa no circuito econômico, incluindo a organização de redes de associações. Segundo Aquino, Castilho e Pires (2009), essas redes possibilitariam um ganho $32 \%$ maior ao vender o material diretamente para as indústrias de reciclagem, se comparado ao das vendas realizadas por intermédio de atravessadores.

Para Duarte (2005), esses trabalhadores organizam-se em associações ou cooperativas como estratégia de enfrentamento ao trabalho árduo e à baixa remuneração, bem como de luta por uma cidadania e uma melhor qualidade de vida. Cunha (2010) acrescenta que essas novas formas de organização têm contribuído para promover a distinção desses trabalhadores como um grupo social legítimo e ressignificar os sentidos que lhes foram originalmente imputados pelos padrões dominantes do consumismo e das identidades socialmente estabelecidas.

Essa ressignificação, em certo sentido, passa pela consciência acerca do papel dos catadores. Esse grupo, aos poucos, começa a atribuir valor a seu trabalho, na medida em que toma consciência de que, por seu intermédio, os resíduos sólidos são reaproveitados, reciclados, transformados em novas matérias-primas. (Maciel et al., 2010).

Essa maior consciência por parte dos catadores não ameniza as condições adversas de trabalho que enfrentam. De forma expressiva, esse segmento da população desenvolve sua atividade em condições extremamente precárias. São milhares de homens e mulheres com peles queimadas e ressecadas pelo sol, que carregam diariamente pelas ruas e avenidas carrinhos pesados, vendem sua força de trabalho sem nenhuma garantia trabalhista e experimentam uma identidade social que os estigmatiza e os humilha.

Em relação a esse último aspecto, pode-se pensar, tomando como referência as ideias de Bauman (2005) sobre o processo de identificação nas sociedades atuais, que os catadores estão entre

[...] aqueles que tiveram negado o acesso à escolha de uma identidade, que não têm o direito de mani- festar as suas preferências e que no final se veem oprimidos por identidades aplicadas e impostas por outros - identidades das quais eles próprios se ressentem, mas não têm permissão de abandonar nem das quais conseguem se livrar. Identidades que estereotipam, humilham, desumanizam, estigmatizam. (Bauman, 2005, p. 44)

Desse modo, os catadores acabam por pertencer a uma subclasse ocupada por aqueles indivíduos que vivem totalmente à margem da sociedade, excluídos da condição de experimentar uma individualidade, de compartilhar o espaço social em que "as identidades são buscadas, escolhidas, construídas, avaliadas, confirmadas ou refutadas" (Bauman, 2005, p. 46). Partindo desse pressuposto, esses indivíduos ficam impossibilitados de vislumbrarem uma identidade própria, escolhida. Por outro lado, os pressupostos de Tajfel (1982) permitem analisar a categoria de catadores a partir do sentimento de pertença grupal. Essa pertença possibilita a construção de uma identidade social compartilhada e imposta, mas ainda assim uma identidade que pode ter aspectos positivos para esses trabalhadores.

As teorias sobre a questão da identidade enfocam diferentes aspectos, especialmente aqueles inerentes ao indivíduo tais como raça, ou os que envolvem suas condições sociais e processos coletivos. Em comparação com a maioria das teorias de identidade, a teoria da Identidade Social de Tajfel não se baseia em pressupostos individuais, mas sim na pertença a um grupo social de referência. Jacques (2007), baseando-se na abordagem sócio-histórica, qualifica a identidade como identidade pessoal, para se referir aos atributos específicos do indivíduo, e identidade social, para se referir aos atributos que assinalam a pertença social, que pode ser, por exemplo, a categoria profissional ou o grupo de trabalho.

Tajfel (1982) compreende Identidade Social como relacionada ao processo de categorização social, determinante nas relações intergrupais. A categorização social desempenha uma função primordial nos processos de organização e classificação da realidade social que, por sua vez, estariam diretamente relacionados aos valores e crenças compartilhados socialmente. Destaca-se que a categorização envolve não somente esses valores e crenças, mas estereótipos que funcionam para confirmar e validar os dados provenientes das interações sociais, mantendo a coerência e a capacidade de previsibilidade. Para o autor, a Identidade Social é "aquela parcela do autoconceito de um indivíduo que deriva do seu conhecimento da sua pertença a um grupo (ou grupos) social, juntamente com o sig- 
nificado emocional e de valor associado àquela pertença". (Tajfel, 1982, p. 290).

De modo específico, a Identidade Social é explicada como um processo decorrente das diferentes posições que o indivíduo ocupa na sociedade, as quais estariam ligadas às diversas pertenças ou filiações sociais. Dessa forma, a Identidade Social de uma pessoa se encontra relacionada com o conhecimento de sua filiação a certos grupos sociais e com a significação emocional e valorativa que resulta dessa filiação. Assim, os indivíduos constroem um tipo de Identidade Social que é alcançada por meio de um processo de diferenciação intergrupal. Nessa diferenciação, os indivíduos atribuem aspectos favoráveis ao seu próprio grupo e desfavoráveis aos grupos com os quais não se identificam. Esse processo possibilita construir uma visão positiva deles próprios, mediada por sentimentos e conhecimentos decorrentes dessa pertença grupal. Em relação aos membros de grupos sociais menos favorecidos, o autor salienta ainda que estes procuram estreitar suas relações e adotam posturas e respostas com a finalidade de melhorar sua autoimagem e alcançar uma mudança social objetiva. Entretanto, quando a pertença a esse grupo não permite a construção de uma Identidade Social positiva, esses indivíduos tentam abandoná-lo, exceto se forem impedidos por motivos objetivos. Nesse caso, procuram mudar a sua avaliação, justificando ou aceitando as características negativas atribuídas ao seu grupo de pertença (Tajfel, 1982).

É importante ressaltar que a Teoria da Identidade Social de Tajfel tem fundamentado pesquisas e teorizações nas mais diversas áreas, tentando compreender os processos intergrupais, por exemplo, nos casos de discriminação e preconceito (Álvaro \& Guarrido, 2006) e, mais recentemente, para compreender esses processos nos contextos organizacionais (Johnson \& Morgenson, 2005). A relação entre trabalho e identidade é apontada por diversos autores (Antunes, 2002; Coutinho, Krawulski, \& Soares, 2007; Jacques, 1996; Moraes, 2009). O trabalho é considerado fator importante na construção da identidade do indivíduo e aspectos como responsabilidade, reconhecimento, dignidade e realização social constituem atributos positivos da identidade do trabalhador (Moraes, 2009). Johnson e Morgenson (2005), baseando-se nas ideias de Tajfel, apontam que no contexto de trabalho pouca importância tem sido dada aos aspectos emocionais na construção da Identidade Social, embora enfatizem que sentimentos positivos em relação ao grupo favorecem a pertença grupal.
A hipótese deste trabalho é a de que mesmo no caso de identidades sociais impostas (Bauman, 2005), o componente afetivo, embora apresente ambiguidades, se configura como um aspecto importante no processo de construção da identidade social. Considerando o que foi dito acerca dos catadores, suas condições de vida e trabalho, suas formas de organização, os avanços na legislação e nas políticas públicas, procurou-se analisar a Identidade Social de catadores de material reciclável tomando como base o sentimento de pertença grupal, seja por fazer parte de uma associação de catadores ou estar vinculado a um depósito que compra e vende material reciclável.

\section{MÉTODO}

Uma vez que para alcançar o objetivo proposto é necessário analisar, de forma minuciosa, uma variedade de informações, optou-se por desenvolver uma pesquisa de cunho qualitativo. Pesquisas dessa natureza podem ser usadas quando a intenção é estudar as relações, as representações, as crenças, as percepções, de um determinado grupo. (Minayo, 2007).

Fizeram parte da pesquisa 29 catadores, 17 homens e 12 mulheres, com idade variando entre 23 e 66 anos, em sua maioria, semianalfabetos, 17 provenientes de associações e 12 de depósitos. Os catadores que participaram da pesquisa foram aqueles que, mediante um convite à associação ou depósito aos quais estavam vinculados, se dispuseram a participar dos grupos focais. Para incentivar a participação dos catadores, os pesquisadores disponibilizaram transporte para o local de realização dos grupos e aqueles que desejaram participar compareceram nos dias e locais previamente informados. Não houve qualquer outro critério de inclusão.

Foram realizados quatro grupos focais. Essa técnica possibilita que cada integrante expresse suas vivências, construídas pelas relações que estabeleceram social e historicamente (Flick, 2004). A opção pela técnica do grupo focal se deu em função da possibilidade de colocar os participantes em uma situação de troca de informações, uma vez que o objeto perseguido se refere às suas condições sociais e ao compartilhamento de uma identidade social.

A quantidade de entrevistas coletivas (grupos) realizada seguiu o critério de saturação das informações. Além disso, os grupos foram mistos, com participantes tanto de depósitos quanto de associações. A participação de catadores das duas categorias seguiu a ideia de que a questão da identidade poderia ser captada em seus aspectos gerais e específicos durante os 
grupos por meio de confrontações no momento das entrevistas grupais. Inicialmente foi solicitado aos participantes que se identificassem, respondendo à pergunta "quem é você". Em seguida, foi pedido que os catadores descrevessem suas atividades diárias e condições de vida.

Os grupos ocorreram em dois locais diferentes: nas dependências da universidade dos pesquisadores e no Centro de Referência em Saúde do Trabalhador do Estado do Ceará (CEREST-CE). Os grupos focais foram realizados com a autorização expressa de cada participante, seguindo as orientações da resolução 196/96 que rege a pesquisa com seres humanos. O projeto foi submetido e aprovado pelo comitê de ética em pesquisa da Universidade de Fortaleza [UNIFOR]. Os participantes foram previamente informados a respeito dos objetivos e procedimentos da pesquisa e da garantia do anonimato das suas colocações. Os discursos foram gravados e em seguida transcritos na íntegra. Esse material foi analisado tendo como base o método do Discurso do Sujeito Coletivo (DSC), que busca resgatar e descrever opiniões, crenças e representações sociais (Lefevre, Lefreve, \& Teixeira, 2000). Embora o DSC se adeque melhor a dados colhidos por meio de entrevistas individuais, seus pressupostos podem ser utilizados para separar ideias chaves dos discursos produzidos nos grupos focais. De acordo com Lefevre e Lefevre (2006), o método é uma proposta de organização e tabulação de dados qualitativos de natureza verbal, obtidos de depoimentos e outros materiais. Consiste basicamente em analisar o material verbal coletado de cada um dos depoimentos, extraindo-se dele as Ideias Centrais e/ou Ancoragens, que podem ser entendidas como categorias, e as suas correspondentes Expressões Chave. Um último passo do método é a construção de um ou mais Discursos do Sujeito Coletivo, compostos pelas Expressões-Chave das Ideias Centrais semelhantes. No caso deste relato, os DSCs foram suprimidos, optando-se pela apresentação apenas das Expressões-chave, uma vez que o esquema da análise se baseia em eixos provenientes da teoria da Identidade Social de Tajfel (1982). Na identificação dos autores das várias Expressões-chave foram utilizadas as iniciais do primeiro nome, seguido do sexo, idade e vinculação.

\section{RESULTADOS}

Os resultados são apresentados a partir dos elementos constitutivos da definição de Identidade Social. Nesse sentido, consideram-se, na apresentação e dis- cussão, os seguintes aspectos: (1) o sentimento de pertença grupal e seu significado emocional e valorativo; (2) a categorização social e a diferenciação intergrupal.

\section{Sentimento de Pertença Grupal e seu Significado Emocional e Valorativo}

Percebe-se que os catadores se definem a partir da sua pertença ao grupo, como mostram as expressõeschave a seguir.

Eu sou alma viva catadora mesma. Eu não faço outra coisa na vida! (L / masculino / 60 anos/ Depósito)

A catadora é aquela que pega o carrinho e sai, não importa se faça chuva ou sol. (C / Feminino / 43 anos / Associação)

Embora essa pertença nem sempre seja vista como positiva:

Eles entendem as coisas [se referindo às pessoas em geral], não é que nem nós, que só entende de catar mesmo. (C / Feminino / 43 anos / Associação)

[Quando me perguntam o que faço] Eu digo que trabalho é de servente, de pedreiro, eu digo que trabalho em qualquer serviço. (F / Masculino / 30 anos / Depósito)

[Minha irmã diz:] Mas esse serviço ai só pra quem é burro. (V / Feminino / 38 anos / Associação)

Trabalha com reciclagem! O pessoal chama a gente sabe de quê? De lixeiro! (A / Feminino / idade não declarada / Associação)

Pros olhos de muitas pessoas, é um trabalho que humilha, meio humilhante, sabe? Tem pessoas que pelo fato de te ver sujo. Carroceiro é ladrão, sabe? Tem tudo isso no meio da reciclagem, nem todos, mas tem muito preconceito. (P / Feminino / 48 anos / Depósito)

A conotação negativa dada à Identidade Social parece se relacionar à falta de alternativa e à necessidade de fazerem parte de um grupo sem qualificação, nesse sentido, possuem uma identidade não escolhida, mas imposta pelas circunstâncias, no sentido proposto por Bauman (2005). 
Ao que parece, a catação, para uma maioria, é compreendida muito mais como uma fonte de renda do que uma atividade associada a uma consciência ambiental ou uma escolha legitima da profissão, como sugerem Maciel et al. (2010). Por outro lado, a catação, por mais penosa que seja, parece permitir a esses indivíduos se assumirem como trabalhadores, mesmo reconhecendo os estereótipos negativos que lhes são atribuídos. Os estereótipos de burro, lixeiro e ladrão, embora estigmatizantes, parecem não ser totalmente incorporados por esses trabalhadores, uma vez que eles não assumem esse discurso como seu, atribuindo-o ao outro.

Vale ressaltar que esses discursos são apresentados tanto por catadores autônomos quanto por associados. Contudo, parece haver no discurso dos associados uma maior consciência acerca da importância da atividade que desenvolvem, fornecendo-lhes uma Identidade Social mais positiva.

Nós trabalhamos limpando a cidade, eu acho que $50 \%$ do lixo vai pro catador, então deixa de ir pro aterro, e lá vai gerar mais crime pra natureza. (C. I Feminino / 43 anos / Associação)

Relacionando esses resultados à definição de Identidade Social apresentada por Tajfel (1982) fica claro que tanto catadores associados quanto autônomos constroem sua Identidade Social a partir do reconhecimento e do sentimento de pertença ao seu grupo. Embora a valoração afetiva apresente certa ambiguidade, ainda assim a Identidade Social é construída a partir do trabalho. Por se tratar de um grupo social desfavorecido, os catadores procuram estreitar relações por meio de associações e adotam um discurso ambientalista com a finalidade de melhorar a autoimagem, principalmente no caso dos catadores associados. Vale destacar que esse mecanismo ocorre em função da percepção da impossibilidade de uma mudança social efetiva, tal como da obtenção de outro trabalho mais valorizado socialmente.

\section{Categorização social e diferenciação intergrupal}

O processo de categorização social se dá pelo reconhecimento do individuo de que pertence a um grupo ou categoria social, o que possibilita definir o seu lugar e o do outro na sociedade. Vale mencionar que para se perceber membro de um grupo é preciso perceber-se diferente dos membros de outros grupos, o que é chamado de diferenciação intergrupal. Desse modo, a categorização social e a diferenciação inter- grupal devem ser compreendidas como inter-relacionadas e constituindo a Identidade Social.

Nesse sentido, esse processo produz percepções estereotipadas, ou seja, a percepção de que todos os membros de uma categoria social ou grupo partilham algumas características que os diferenciam de outras categorias. $\mathrm{O}$ processo de estereotipia se dá em virtude da necessidade de esses membros manterem uma imagem positiva deles próprios, o que os leva a avaliar os membros dos outros grupos de forma negativa (Deschamps \& Moliner, 2009).

A categorização social e a diferenciação intergrupal são percebidas nos discursos dos catadores. Os catadores procuram se diferenciar de grupos sociais considerados ainda mais negativos (vagabundos $\mathrm{e}$ marginais), em uma tentativa de se avaliar de forma positiva:

Eu durmo na rua, aí quando é de manhã, vou pra carroça trabalhar; não vou é vagabundar, né?! Não vou roubar. (C / Masculino / 38 anos / Depósito)

Defendem-se das imagens negativas da profissão em um processo de comparação social - "são tudo isso, mas são trabalhadores e não vagabundos”. Além disso, enquanto trabalhadores que reciclam o lixo comparam-se e se diferenciam dos chamados garis:

Aí se nós tivéssemos alguém que reconhecesse nosso trabalho e nos pagasse como pagam o gari. O gari é pago. E nós trabalhamos melhor que o gari, porque além de fazer o trabalho dele, nós reciclamos, nós estamos lucrando com o material. $O$ gari não se preocupa em deixar uma pet no chão, ou um pneu, eles jogam pra outro canto. E nós não, quando chegamos no lugar retiramos todo o material, depois amarrar a boca do saco, nós já fomos treinados pra saber como coletar. (C / Feminino / 43 anos / Associação)

Pra nós uma catadora de reciclagem que nem nós, que depende do material, não tem carro do ano, não tem casa toda na cerâmica, não tem filho que estuda na melhor escola particular. Nós não temos nem uma chinela boa pra calçar, imagine carro do ano. [...] E o que a gente busca na associação [...] lá da Rede é que os próprios catadores tomem de conta da associação. [...] Dentro da Associação, nós formemos um grupo. [...] $O$ nosso sonho não é de ter riqueza, de ter dinheiro, o nosso sonho é de crescer dentro da associação. (C / Feminino / 43 anos / Associação)

Interação Psicol.,Curitiba, v. 16, n. 2, p. 239-247, jul./dez. 2012 
Essas falas ressaltam, também, que as características percebidas em um grupo acentuam os sentimentos de pertença grupal, quando comparadas às diferenças percebidas em outros grupos. Os discursos dos catadores permitem identificar o componente cognitivo desse processo, referente à inclusão racional da pertença, quando ressaltam que para realizar o trabalho de catação há certa sabedoria e treinamento; e os componentes avaliativo e emocional, no sentido da conotação positiva ou negativa dessa pertença e das emoções que acompanham esse conhecimento, quando se avaliam como "melhores" que os garis e significam a pertença à associação como possível de transformação de sua condição de vida. $\mathrm{O}$ aspecto avaliativo e emocional da identificação grupal manifesta-se no favoritismo do "endogrupo" em detrimento do "exogrupo", denominações do próprio grupo e do outro grupo, respectivamente, utilizadas por Tajfel (citado por Álvaro \& Garrido, 2006).

Outra possibilidade de diferenciação e comparação aparece nas falas dos catadores quando se referem ao catador de "carroça" e de "saco"1.

Tem muitos carroceiros que usam drogas, não todos, mas a maioria usa, eles passam o dia inteiro principalmente as pessoas que trabalham com o saco. (P / Feminino / 48 anos / Depósito)

Não são todos não, mas a maioria dos carroceiros tem dias que anda com saco, prá arranjar o dinheiro do vício, da lombra deles. (M / Masculino/ 26 anos/ Associação)

Considerando que os indivíduos buscam um quadro de referência que favoreça o eu, essas situações podem implicar o desejo de mudança para outros grupos de referência, avaliados de forma mais positiva. Contudo, nem sempre essa solução é possível. No caso dos catadores, eles não podem abandonar o grupo por motivos objetivos, uma vez que possuem pouca ou nenhuma qualificação profissional e os ganhos do trabalho são suficientes apenas para a sua sobrevivência, conforme discursos a seguir.

Eu queria ser um vendedor ambulante. Porque eu queria depender de mim mesmo, né? (M/ Masculino/ 25 anos/ Depósito)

Se eu pudesse mesmo eu queria ser manicure. [...] Eu queria botar pra frente o curso de manicure, né, porque eu já, mas aí eu não tenho condição de com- prar o material, mesmo que nada. (L/ Feminino/ 38 anos/ Depósito)

A carteira assinada tem o direito a pagar o INSS que a gente não paga. (F/Feminino/ 47 anos/ Associação)

Assim, na impossibilidade de abandonar seu grupo de identificação, os catadores se empenham em modificar a sua avaliação, tentando justificar ou aceitar as características negativas, como mostra a fala a seguir.

Minha irmã! Vai procurar outro meio de vida pra tu. Ai eu digo: homi, deixa eu, tu tem tua vida já ganha, eu não tenho não. Ai ela fica dizendo que meu emprego não é digno, que ela não tem a menor condição de sair puxando a carroça. Ai pronto. Vergonha eu tenho de roubar e matar, agora de puxar a carroça não tenho não. (V / Feminino/ 38 anos/ Associação)

Em resumo, percebe-se o mecanismo de comparação/diferenciação dos catadores entre Nós e Eles, o reconhecimento de aspectos negativos no grupo, o desejo de deixar o grupo e a impossibilidade disso. Os catadores assumem a Identidade Social do grupo de trabalho, como preconizado por Tajfel (1982), mas essa é uma identidade imposta, no sentido de Bauman (2005), e há o desejo de pertença a outros grupos mais valorizados.

A realidade dos catadores parece ser vivenciada de forma diferente pelos trabalhadores vinculados aos depósitos e às associações, como mostra a expressão chave a seguir.

Tivemos uma reunião [se referindo ao grupo de associados] semana retrasada e fechamos nosso grupo, porque só ia ficar aquele que acreditasse, tinha que acreditar, aqueles que não acreditassem não iam ficar. Aí fizemos a reunião e relatamos na ata o que nós concordamos. Os primeiros [carrinhos] nós compramos com o dinheiro da associação quando começamos. Porque foi através do lixo que conseguiu espaço. Aí a gente começou a lutar [...] Cada associação tem um presidente, seu representante. Fomos lá no Banco do Brasil e lá conseguiu ganhar. Cada associação consegue carrinhos e agora estamos lutando pela nossa balança... (C / Feminino / 43 anos / Associação)

Essa pertença torna possível o desenvolvimento de formas de identificação ligeiramente distintas. Os 
catadores associados parecem ter mais consciência da legitimidade de seu trabalho, das condições de vida impostas pela sociedade e da não transitoriedade dessa realidade, havendo assim um fortalecimento do sentimento de pertencimento a um grupo que se iguala pela exclusão e invisibilidade social, mas que se diferencia pelo significado atribuído à atividade que realiza.

\section{CONCLUSÃO}

De uma forma geral, os catadores reconhecem a condição de exclusão a que estão submetidos, seja pela falta de oportunidades no mercado de trabalho, seja pela forma negativa como são vistos pela sociedade em decorrência da atividade que desenvolvem e dos estereótipos que lhes são atribuídos. Entretanto, esses indivíduos também se reconhecem como trabalhadores na medida em que percebem no trabalho de catação a única alternativa de sobrevivência. Contudo, a identidade de trabalhador permite que esses sujeitos tenham uma visão positiva deles próprios, especialmente quando essa os diferencia dos desocupados, dos que roubam, dos vagabundos. Desse modo, a Identidade Social é resultado tanto da necessidade de diferenciar o eu em relação aos outros, como de ser reconhecido como pertencendo a um grupo. (Brewer, 1999).

Os catadores pesquisados, tanto de associações quanto de depósitos, constroem uma identidade de trabalhador, tal como propõe Tajfel (1982) quando defende a formação da identidade como decorrente do sentimento de pertença a um grupo social e do significado atribuído a esse grupo, mesmo que a pertença a esse grupo esteja ligada a condições básicas de sobrevivência e o grupo reúna indivíduos socialmente desvalorizados. A pertença a esse grupo, embora estigmatizado, permite a esses trabalhadores se diferenciarem de grupos ainda menos valorizados socialmente, como o de "ladrão" ou "marginal". No caso dos catadores pesquisados, esse sentimento está associado ao fato de fazerem parte de uma categoria de trabalhadores e da crescente importância que vem sendo atribuída à atividade que desempenham para a sociedade.

Analisando os discursos dos catadores associados e dos vinculados a depósitos, destaca-se uma visão mais critica por parte dos primeiros acerca do papel que desempenham na sociedade. Acredita-se que essa criticidade advém da realidade de grupo que é vivenciada por esses catadores, que enxergam nessa forma de organização a possibilidade de mudança da realidade social que vivem e de como são percebidos socialmente.
Como destaca Cunha (2010), as associações e cooperativas funcionam como elemento de distinção entre o catador de rua e o organizado, refletindo uma nova forma de mobilização política. Os catadores associados buscam formas alternativas de reconhecimento social, que ocorrem pela valorização da identidade e a criação de oportunidades que favoreçam a visibilidade do grupo. Esse movimento teria como objetivo, por um lado, a superação das adversidades e o crescimento econômico da atividade de catação e, por outro, a inclusão e o reconhecimento social dos que a realizam, por meio da criação de espaços institucionais e simbólicos que favoreçam a construção e solidificação da identidade e dignidade de grupo dos catadores.

\section{REFERÊNCIAS}

Álvaro, J. L., \& Garrido, A. (2006). Psicologia social: Perspectivas psicológicas e sociológicas. São Paulo: McGraw-Hill.

Antunes, R. (2002). Adeus ao trabalho? Ensaio sobre as metamorfoses e a centralidade do mundo do trabalho. São Paulo: Cortez - Campinas: UNICAMP.

Aquino, I. F., Castilho Junior, A. B., \& Pires, T. S. L. (2009). A organização em rede dos catadores de materiais recicláveis na cadeia produtiva reversa de pós-consumo da região da grande Florianópolis: Uma alternativa de agregação de valor. Gestão $e$ Produção, 16, 15-24.

Associação Brasileira de Empresas de Limpeza Pública e Resíduos Especiais (ABRELPE). (2009). Panorama dos resíduos sólidos no Brasil, Edição 2009. Retirado de

Bauman, Z. (2005). Identidade (C. A. Medeiros, Trans.). Rio de Janeiro: JZE.

Brewer, M. B. (1999). The psychology of prejudice: Ingroup love or outgroup hate? Journal of Social Issues, 55, 429-444.

Coutinho, M. C., Krawulski, E., \& Soares, D. H. P. (2007). Identidade e trabalho na contemporaneidade: Repensando articulações possíveis. Psicologia \& Sociedade, 19, 29-37.

Cunha, M. R. (2010). Eu vivo do lixo: A identidade dos catadores de materiais recicláveis de Goiânia. In Grupos de Estudos de Políticas da América Latina (GEPAL) (Ed.), Anais do IV Simpósio Lutas Sociais na América Latina: Imperialismo, nacionalismo e militarismo no Século XXI. Retirado de http://www.uel.br/grupo-pesquisa/gepal/ anais_ivsimp/gt5/16_MarinaRoriz.pdf

Deschamps, J. C., \& Moliner, P. (2009). A identidade em psicologia social: Dos processos identitários às representações sociais (L. Orth, Trans.). Petrópolis: Vozes

Duarte, H. A. (2005). A gestão dos catadores de material reciclável e o modelo cooperativo. (Dissertação de mestrado). Universidade Católica de Santos. Retirado de http://biblioteca.unisan tos.br/tede/tde

Flick, U. (2004). Uma introdução à pesquisa qualitativa (S. Netz, Trans.). Porto Alegre: Bookman. 
Instituto de Pesquisa Econômica Aplicada (IPEA) (2010). Relatório de pesquisa sobre pagamento por serviços ambientais urbanos para gestão de resíduos sólidos. Brasília: IPEA.

Jacques, M. G. (1996). Identidade e trabalho: Uma articulação indispensável. In A. Tamayo, J. E. Borges-Andrade \& W. Codo (Eds.), Trabalho, organizações e cultura (pp. 41-47) São Paulo: Coletâneas da ANPEPP..

Jacques, M. G. (2007). Identidade. In M. G. Jacques, M. Strey, M. Bernardes, P. Guareschi, S. Carlos \& T. Fonseca (Eds.), Psicologia social contemporânea (pp. 161-167). Petrópolis: Vozes.

Johnson, M. D., \& Morgeson, F. P. (2005). Cognitive and affective identification in organizational settings. In Academy of Management (Ed.), 65th Annual Meeting of the Academy of Management. Honolulu, HI: Academy of Management. Retirado de http://faculty. washington.edu/mdj3/Conferences/ Academy/Proceedings.pdf.

Juncá, D. C. M. (2001). Vida de catador: Outras palavras sobre o lixo. Cadernos do CEAS, 193, 61-68.

Juncá, D. C. M. (2004) Mais que sobras e sobrantes: Trajetória de sujeitos no lixo (Tese de doutorado). Fundação Oswaldo Cruz, Rio de Janeiro.

Lefevre, F., Lefevre, A. M. C., \& Teixeira, J. V. (2000). O discurso do sujeito coletivo: Uma nova abordagem metodológica em pesquisa qualitativa. Caxias do Sul: EDUCS.

Lefevre, F., \& Lefevre, A. M. C. (2006). O sujeito coletivo que fala. Interface - Comunicação Saúde Educação, 10, 517-524.

Lei n. 12.305, de 02 de agosto de 2010. Institui a Política Nacional de Resíduos Sólidos. Brasília. Diário Oficial da União, seção 1. Retirado de http://www.in.gov.br/visualiza/index.jsp?jor nal $=1 \&$ pagina $=3 \&$ data $=03 / 08 / 2010$

Maciel, R. H., Santos, J. B. F., Matos, T. G. R., Meireles, G. F., Vieira, M. E. A., \& Fontenelle, M. F. (2010). Work, health and organisation of street scavengers in Fortaleza, Brazil. Policy and Practice in Health and Safety, 8, 95-112.
Medeiros, L. F. R., \& Macedo, K. B. (2006). Catador de material reciclável: Uma profissão para além da sobrevivência? Psicologia \& Sociedade, 18, 62-71.

Medeiros, L. F. R., \& Macedo, K. B. (2007). Profissão: Catador de material reciclável, entre o viver e o sobreviver. Revista Brasileira de Gestão e Desenvolvimento Regional, 3, 72-94.

Minayo, M. C. S. (2007). Pesquisa social: Teoria, método e criatividade. Petrópolis: Vozes.

Ministério do Trabalho e Emprego. (2010). Classificação Brasileira de Ocupações. Retirado de http://www.mtecbo.gov.br/ cbosite/pages/home.jsf

Moraes, A. B. (2009). Identidade e trabalho: Um relato sobre as produções científicas brasileiras. In $X V$ Encontro Nacional da ABRAPSO. Maceió: ABRAPSO. Retirado de https://docs. google.com/viewer?url=http $\% 3 \mathrm{~A} \% 2 \mathrm{~F} \% 2 \mathrm{Fwww}$.abrapso.org.br\%2 Fsiteprincipal\%2Fimages\%2FAnais_XVENABRAPSO $\% 2 \mathrm{~F} 3$ $65 . \% 2520$ identidade $\% 2520 \mathrm{e} \% 2520$ traba lho.pdf

Sousa, C. M., \& Mendes, A. M. (2006). Viver do lixo ou no lixo? A relação entre saúde e trabalho na ocupação de catadores de material reciclável cooperativados no Distrito Federal - Estudo exploratório. Psicologia: Organizações e Trabalho, 6, 62-71.

Tajfel, H. (1982). Grupos humanos e categorias sociais: Estudos em psicologia social. Lisboa: Livros Horizonte.

Nota:

1 "Catar no saco" significa recolher materiais recicláveis com o auxílio apenas de sacos plásticos. Esses catadores conseguem uma quantidade pequena de materiais em comparação com os que se utilizam de "carroças" e estão associados ao uso de drogas (Maciel et al., 2010). 